der gewaltigen Themenkreise Gerechtigkeit widerfahren zu lassen. Dies ist zunächst ein zwar notwendiger und lobenswerter Ansatz. Er muß aber zu einem ausufernden Hinund-Her-Gerede verkommen, wenn er auf eine solche komplizierte Materie wie Weltmission und Kolonialismus trifft. Denn - und dies verdeutlicht die Untersuchung Hammers - es gibt weder "die Mission", noch "den Kolonialismus", sondern eine Vielzahl unterschiedlicher, widersprüchlicher und dann auch wieder in manchem übereinstimmender missionarischer und kolonialer Aktivitäten.

Hier wäre eine Selbstbeschränkung für Autor und Leser segensreich gewesen. Die Fülle der angerissenen Detailausführungen - unvermeidbar wegen der Komplexität der Problembereiche - verstellt den Blick auf das Wesentliche, auf das, was man gerne als die "Lehre aus der Geschichte" bezeichnet; denn jede historische Untersuchung gerade in dem angesprochenen Bereich sollte doch wohl auch einen Deuterahmen für aktuelle Fragestellungen abgeben. Hierin läßt Karl Hammer seine Leser im Stich. Oder anders gesagt: Seine Methode, an die gestellte Aufgabe heranzugehen, erweist sich als im höchsten Maße ungeeignet.

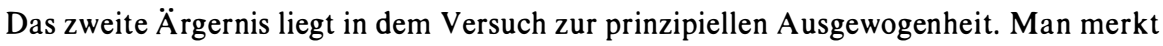
die Absicht - und ist verstimmt. Es hilft - weiß Gott! - nicht weiter, wenn man - in altbewährter Manier Selbstentschuldung durch Schuldverteilung betreibend - feststellt, daß es überall gute und schlechte Menschen gibt und somit sowohl die Missionare wie die Missionierten, die Kolonialmächte wie die Kolonien Dreck am Stecken haben.

Was das Buch dennoch lesenswert macht, sind vor allem die in Teil II und III gesammelten historischen Fakten. Hier läßt sich viel Wissenswertes finden. Karl Hammer hätte es bei dieser Sammlung belassen sollen.

In der Zusammenfassung am Ende seines Bandes beurteilt der Autor seine Untersuchung: "Dieser Band hat die angerissenen Probleme nicht generell lösen können und wollen." In der Tat.

Gerd Höft

\title{
A.J.G.M. Sanders
}

\section{International Jurisprudence in African Context}

Butterworth, Durban, 1979, 259 S.

Sanders ist Senior Researcher am Institute of Foreign and Comparative Law der University of South Africa und Herausgeber der Lesotho Law Reports und der Swaziland Law Reports. Sein Buch verfolgt das Ziel, in die grundlegenden Theorien über Völkerrecht einzuführen und die Stellung Afrikas in der Völkerrechtsordnung zu beschreiben. Der Autor wählt einen eigentümlichen Weg, um dieses Ziel zu erreichen: Er stellt ein Kapitel über 'Africa in the International Legal Order - the Emergence of a Region (S. 48-154) zwischen zwei Abschnitte, die in konventioneller, lehrbuchartiger Manier über das Problem der Existenz des Völkerrechts (S. 3-45) bzw. über Entstehungstheo- 
rien, Quellen, Völkerrechtssubjekte sowie das Verhältnis von Völkerrecht zu innerstaatlichem Recht informieren ('On the Identification of International Law', S. 157-232). Sanders versucht also nicht eine Einführung in das Völkerrecht, die sich primär an afrikanischem Material orientieren würde oder af rikanischen Anschauungen und Traditionen besonderes Gewicht gäbe, wie man angesichts des Titels erwarten kann. Die insoweit klaffende Lücke, durch Taslim O. Elias nur zum geringen Teil geschlossen, ${ }^{1}$ besteht also nach wie vor.

Davon abgesehen ist positiv zu bemerken, daß Sanders kundig, knapp und präzise in die völkerrechtliche Diskussion einführt. Das Afrika gewidmete Herzstück des Bandes gliedert sich in einen Abschnitt über präkoloniales Afrika, die Kolonialzeit und 'The Africa of Today‘. Die soziologischen Besonderheiten der frühen afrikanischen Gesellschaften werden deutlich gemacht. Die Penetration Afrikas wird als ökonomisch inspiriert geschildert, ihre rechtliche Absicherung kritisch analysiert. Die Kolonialzeit erscheint völkerrechtshistorisch als Episode, Kontinuitäten zwischen altem und heutigem Afrika sucht der Autor allenthalben zu betonen.

Natürlich drängt sich die Frage auf, in welcher Weise der in Südafrika lehrende Sanders zu den die Völkerrechtsdiskussion im Schwarzen Afrika gegenwärtig am meisten bewegenden Fragen der Legitimität von Gewalt und Unterstützung von Gewalt gegen Apartheid, der Menschenrechte, der Rechtslage von Namibia Stellung nimmt: Er klammert diese Fragen weitgehend aus, konstatiert sie gelegentlich (S. 82, 134), weicht aber in die Rolle desjenigen aus, der Probleme nur benennt, Auffassungen anderer mitteilt (gelegentlich undifferenziert: "the African States"), aber selbst nicht Stellung bezieht. Man bemerkt gleichwohl ein bisweilen erstaunliches Einfühlungsvermögen für das Selbstverständnis afrikanischer Staaten und ihre Bemühung um Veränderung völkerrechtlicher Normeninhalte. Fazit danach: ein Buch, das seinem Titel nicht voll gerecht wird, aber kenntnisreich geschrieben ist, das Defizite aufweist, die aus seiner Herkunft erklärbar sind, aber gerade im Hinblick darauf auch durch Offenheit und Feinfühligkeit überrascht.

Philip Kunig

\section{Margaret Strobel}

\section{Muslim Women in Mombasa 1890-1975}

Yale University Press, New Haven \& London, 1979, 258 S.

Die hier vorliegende Dissertation ist der Versuch die Geschichte moslemischer Frauen Kenias, und hier vor allem der Küstenstadt Mombasa, darzustellen. Die Schwierigkeit der Untersuchung liegt darin, daß die Autorin sich weitgehend auf mündliche Uberliefe-

1 Vgl. meine Besprechung von T. O. Elias, New Horizons in International Law, VRU 13 (1980), S. 185. 